\title{
El comienzo de las relaciones diplomáticas entre España y la República Dominicana en 1855
}

\author{
Luis Alfonso Escolano GimÉNEZ \\ Universidad Iberoamericana \\ 1.escolano@unibe.edu.do
}

Recepción: 4 de octubre de 2010 / Revisión: 4 de diciembre de 2010

Aceptación: 11 de marzo de 2011 / Publicación: diciembre de 2011

\begin{abstract}
RESUMEN
El comienzo de las relaciones diplomáticas entre España y la República Dominicana se vio afectado por las dificultades derivadas de la compleja situación política interna dominicana. La coyuntura internacional había comenzado a cambiar y ya no era posible confiar la defensa de Cuba y Puerto Rico tan sólo a la acción combinada de Francia y Gran Bretaña, como único medio de obstaculizar el expansionismo estadounidense en las Antillas. Por ello, el gobierno español siguió adelante con su plan de establecer relaciones diplomáticas con la República Dominicana, asunto que estimaba imprescindible para ejercer una influencia directa sobre el ejecutivo de Santo Domingo.
\end{abstract}

Palabras clave: Relaciones diplomáticas hispano-dominicanas, expansionismo estadounidense, rivalidad internacional, injerencia externa, Antillas, República Dominicana, siglo XIX.

\section{The start of diplomatic relations between Spain and the Dominican Republic in 1855}

\begin{abstract}
The start of diplomatic relations between Spain and the Dominican Republic was affected by the difficulties arising from the complexity of Dominican internal political situation. The international situation had begun to change and was no longer possible to entrust the defense of Cuba and Puerto Rico solely to the combined action of Great Britain and France, as the only means of impeding the expansionism of United States in the Antilles. Therefore, the Spanish government continued its plan to establish diplomatic relations with the Dominican Republic, as it was essential for exerting a direct influence on the executive of Santo Domingo.
\end{abstract}

Keywords: Spanish-Dominican Diplomatic Relations, United States Expansionism, International Rivalry, Foreign Interference, Antilles, Dominican Republic, $19^{\text {th }}$ Century.

SUMARIO: 1. Introducción. 2. El complicado inicio de las relaciones hispano-dominicanas. 3. La situación política interna de la República Dominicana y sus implicaciones internacionales. 4. Las represalias del régimen de Santana contra súbditos españoles y la polémica en torno a la matrícula consular. 5. La nueva actitud de Gran Bretaña y Francia frente al tratado dominico-norteamericano. 6. El establecimiento de relaciones diplomáticas entre España y la República Dominicana. 7. Conclusiones. 8. Referencias bibliográficas. 


\section{INTRODUCCIÓN}

La primera década de vida independiente de la República Dominicana, tras su separación de Haití en 1844, había transcurrido en medio de los sobresaltos derivados tanto de las continuas invasiones haitianas, como de las no menos graves disensiones internas. Esta situación de inestabilidad crónica había hecho de la joven república un escenario ideal para la permanente injerencia extranjera en sus asuntos, a menudo con el pretexto de defender la paz entre las dos naciones en que está dividida la isla. Los diversos intentos realizados por los dos presidentes que se venían alternando en el poder, a fin de obtener protección más o menos directa por parte de alguna potencia, despertaron la rivalidad entre los países con mayores intereses en el área antillana: los Estados Unidos, España, Francia y Gran Bretaña.

El peligro que suponía la posibilidad de un tratado dominico-estadounidense era bien conocido por el gobierno español, que temía que la presencia norteamericana en la República Dominicana fuera sólo un primer paso para lanzarse al ataque contra sus posesiones de Cuba y Puerto Rico. El ejecutivo de Santo Domingo trató de mantener abierto en todo momento el mayor número posible de opciones, por lo que no dudó en jugar a dos bandas en la negociación de sendos tratados, aun a sabiendas del interés de España en impedir la penetración norteamericana. Este fue sin duda el principal objetivo que llevó al gobierno español a firmar el tratado de 1855, ya que lo consideraba la mejor herramienta para posicionarse en el terreno de juego geoestratégico con unas mayores probabilidades de éxito.

En tal sentido, no deben olvidarse los precedentes que sentó la anexión, norteamericana de los territorios situados al norte del Río Grande entre 1845 y 1848 , ni el filibusterismo de William Walker, quien con ayuda de un grupo de aventureros se hizo con el control de Nicaragua en 1855. Resultado de todo ello fue que la rivalidad hispano-estadounidense aumentó en toda el área caribeña, así como en el resto de América, al mismo tiempo que España superaba las debilidades que se había visto obligada a afrontar durante los años anteriores. De hecho, la confluencia de los problemas europeos y americanos durante las décadas de 1850 y 1860 fue tan profunda que su intensidad es incomparable con la de las dos décadas anteriores ${ }^{1}$. Efectivamente, a partir de la segunda mitad del siglo XIX, el Caribe y el golfo de México "se convirtieron en el escenario de un particular enfrentamiento geopolítico" entre Europa y los Estados Unidos. España tuvo que enfrentarse a la creciente presión norteamericana sobre Cuba y Puerto Rico, por lo que intentó "extender su área de influencia a otros países de la región, como México y la República Dominicana", con el fin de poner freno al "expansionismo estadounidense sobre sus colonias antillanas". Cabe recordar que en 1856 los estadounidenses eligieron presidente al candidato del partido demócrata, James Buchanan, para cuya elección fueron de vital importancia sus credenciales expansionistas, que le permitieron ganar el voto sureño ${ }^{3}$.

\footnotetext{
${ }^{1}$ Cortada, 1978, pp. 69-77.

2 SÁnchez, 2007, p. 489.

${ }^{3}$ Martínez-Fernández, 1992, p. 80.
} 
Aun cuando las crecientes divisiones internas acerca del asunto de la expansión de la esclavitud dificultaban un decidido avance del expansionismo norteamericano en el Caribe, se puede afirmar que los Estados Unidos aumentaron su influencia sobre la región a lo largo de la década de 1850. Sobre todo en el período posterior al denominado temor a la africanización de Cuba, entre 1853 y 1854, los Estados Unidos trataron de negociar una vía para establecer un imperio antillano con posesiones en Cuba, codiciada por los expansionistas sureños, y la República Dominicana, objetivo de los expansionistas del norte. Ambos intentos fracasaron por diversas razones, entre las que debe subrayarse la oposición en el interior de los Estados Unidos, pero también la ejercida por las potencias marítimas europeas, así como la existente dentro de Cuba y la República Dominicana ${ }^{4}$.

\section{ELCOMPLICADO INICIO DE LAS RELACIONES HISPANO-DOMINICANAS}

A pesar de la agitación política reinante en la República Dominicana, o quizás debido a ella, Santana transmitió al agente comercial de los Estados Unidos su interés en reanudar las negociaciones tendentes a la firma de un tratado de reconocimiento, tras la interrupción sufrida por el mismo en 1854, como consecuencia de la intervención europea para entorpecerlo. El gobierno español seguía atentamente la evolución de los acontecimientos en la República Dominicana, para lo que contaba con la información suministrada por su agente comercial en Santo Domingo, pero también con la colaboración de los representantes diplomáticos británicos y franceses. Así, el 21 de enero de 1855 lord Howden, ministro plenipotenciario de Gran Bretaña en Madrid, comunicó al ministro de Estado lo siguiente:

I lose no time in informing Your Excellency that Mr. Cazneau [...] had requested permission to withdraw altogether the Treaty which he had presented, but that, by the lost advices from that quarter, the Dominican Government had not answered the Note, and are even still in doubt whether they would comply with Mr. Cazneau's desire, or refuse to do so, submitting the Treaty to the Assembly 5 .

El 2 de febrero de 1855, mientras en Madrid se negociaba el tratado de reconocimiento hispano-dominicano, el agente comercial de España en Santo Domingo, Eduardo San Just, expresó sus temores con respecto a las verdaderas intenciones del gobierno dominicano, que cada día estaba "más y más inclinado a favorecer las pretensiones de los Estados Unidos". De hecho, era tal "su descaro" que había llegado

\footnotetext{
${ }^{4}$ Ibidem, pp. 94-95.

5 "No pierdo ni un momento en informar a su excelencia de que el señor Cazneau pidió permiso para retirar completamente el tratado que él había presentado, pero que, según las últimas noticias de esa parte, el gobierno dominicano no había respondido a la nota, e incluso dudaban todavía si cumplirían los deseos del señor Cazneau, o se negarían a hacerlo, sometiendo el tratado a la Cámara". (La traducción es nuestra). Carta de Howden a Luzuriaga. Madrid, 21-I-1855. Archivo del Ministerio de Asuntos Exteriores, Madrid (en adelante: AMAE), fondo Política, subfondo Política Exterior, serie R. Dominicana, Leg. H 2374.
} 
incluso a expresar sus ideas al respecto en un escrito publicado en la misma Gaceta Oficial. Por los términos de dicho artículo, San Just dedujo que "las intrigas" del agente especial de los Estados Unidos, William L. Cazneau, un comerciante, político y militar que había tomado parte en la anexión de Texas, iban "adelantando de tal suerte que sus proyectos" hallaban "la mejor acojida [sic] entre los hombres" que habían quedado al frente de la administración en ausencia de Santana, quien sin "la menor duda" estaba "de acuerdo con los mismos". Acto seguido, expuso con claridad cuál era "el único medio de terminar tan desagradable situación", que consistía en "oponer por la fuerza la más vigorosa resistencia a las pretensiones que los Estados Unidos" tenían "sobre estos países". San Just también se refirió en su comunicación a la opinión del pueblo dominicano con respecto a las relaciones exteriores de su país, y la calificaba como "favorable a las potencias occidentales, de Europa, y particularmente a la España". En este sentido, señaló que el gobierno de Santana rechazaba dicha opinión "por un interés puramente personal". Para apoyar sus duras críticas contra esta política pro-norteamericana del gobierno dominicano, el representante español en Santo Domingo resaltó además el importante hecho de que los cónsules de Francia y Gran Bretaña en Santo Domingo no podían "menos que demostrar públicamente el profundo disgusto", de que estaban "presos", e invitaban a sus respectivos gobiernos "a tomarlo en consideración sin pérdida de tiempo"6.

Sin embargo, la oposición británica y francesa a la firma de un tratado dominiconorteamericano se limitaría en adelante al rechazo de concesiones territoriales a los Estados Unidos, y aun esa postura de los cónsules se vio muy matizada por la de sus respectivos gobiernos. El caso de Gran Bretaña es especialmente llamativo, puesto que el cambio de su política "con respecto a los Estados Unidos y Francia alrededor de 1855, significó también un giro en la actitud frente a las actividades de España en el Caribe". De este modo, una vez que el gobierno de Londres "dejó a un lado la oposición activa a la expansión norteamericana y francesa [...], no necesitó usar a España de amortiguador frente a sus dos antiguos rivales". Por medio de esta nueva política, Gran Bretaña no sólo trataba de ahorrarse complicaciones con los Estados Unidos y Francia, sino que también "esperaba evitar el efecto desgarrador que una guerra franco-española o hispano-americana tendría en sus intereses comerciales" , intereses que constituían al fin y al cabo el motor y la razón principales de su influencia en el área caribeña.

Tan sólo cinco días después de enviar la comunicación anterior, San Just volvió a dirigirse al gobernador de Cuba, general De la Concha, para darle noticia de los últimos sucesos que habían tenido lugar en la República Dominicana. El agente comercial español le informó que el 26 de enero habían fondeado en la bahía de Samaná dos barcos norteamericanos de guerra, mientras que otros se dirigían a la capital, todos ellos con el objetivo de apoyar las gestiones de Cazneau ante el gobierno dominicano. Acto seguido, San Just manifestó su opinión al respecto, y señaló que "esto es tanto más fácil en este momento cuanto que [...] los Ministros del Presidente Santana están enteramente de acuerdo con las ideas del enviado Norteamericano". Dado que el presidente no se

${ }^{6}$ Carta de Eduardo San Just al gobernador de Cuba. Santo Domingo, 2-II-1855. AMAE, fondo Política, subfondo Política Exterior, serie R. Dominicana, Leg. H 2374 (Es copia).

${ }^{7}$ Hauch, 1996, p. 125. 
encontraba en la capital, su ausencia parecía estar siendo aprovechada por los miembros del gobierno decididamente partidarios del tratado para hacer avanzar más deprisa la negociación del mismo. Sin embargo, el representante español en Santo Domingo se mostró pesimista con respecto a que el anunciado regreso de Santana contribuyese a mejorar las cosas. San Just señaló que su vuelta ya no rebajaría "un quilate al valor de la actual situación", dado que "ni por su capacidad ni por los compromisos" que había contraído le era posible "desprenderse de los hombres" que le acompañaban en el gobierno, por lo que aprobaría "forzosamente", o incluso "de buena voluntad", cuanto aquéllos decidieran ejecutar. Esto no significa que San Just considerase a Santana libre de sospecha en el asunto del tratado con los Estados Unidos, pero sí puede deducirse de sus comentarios una cierta resistencia a cargarle con toda la responsabilidad, mientras que no dudaba en adjudicar la mayor parte de la misma a sus colaboradores. Frente a un gobierno que, en su opinión, se había echado en brazos de Cazneau, el agente indicó el camino por medio del cual España podría reconducir la política dominicana en un sentido más favorable a sus intereses, y se refirió a que durante los días anteriores se había hablado "con bastante seguridad de la próxima vuelta de Báez al país", para derrocar a Santana. Según San Just, en esas circunstancias su triunfo ofrecería a España "una completa seguridad acerca de los proyectos de los Yankees y no sería dudoso si se presentara pues el pueblo desea vivamente su regreso ${ }^{8}$.

Así, la intervención en la lucha política interna dominicana se iba abriendo paso como el modo más rápido de solucionar una situación que no parecía tener fácil salida si continuaban en el poder las mismas personas. Además, el régimen de Santana se había endurecido de forma considerable sobre todo a partir de la promulgación en diciembre de 1854 de una nueva Constitución, lo que había provocado que el descontento de la población dominicana fuera en aumento y volviese los ojos al caudillo rival de Santana, que era el ex presidente Báez. El periódico El Porvenir, cuyo objetivo era "llevar de nuevo a Báez al poder y, por tanto, combatir al santanismo" se atrevió a reclamar un "gobierno republicano moderado", a pesar del creciente peligro que entrañaba oponerse abiertamente al carácter cada vez más dictatorial de aquel régimen político. El mencionado periódico defendió en octubre de ese año la necesidad de reformas que garantizasen "la libertad de palabra y de prensa [y] la perfecta igualdad de todos ante la ley", pero sin resultado alguno, por lo que sus responsables decidieron suspender la publicación. En estas circunstancias, los seguidores de Báez se dieron cuenta de que "la vía legal para alcanzar el poder [...] estaba cerrada" para ellos?.

La apuesta por Báez que hicieron los cónsules británico y francés, desde que Santana mostró sus veleidades pro-norteamericanas, no escapaba a la atención del agente de los Estados Unidos en Santo Domingo, quien advirtió a su gobierno de que los franceses intentaban derribar a Santana "para encumbrar otra vez a la Presidencia al mulato Báez, que odia a los Estados Unidos y a todos los americanos, y quien es netamente francés de corazón”"10.

${ }^{8}$ Carta de Eduardo San Just al gobernador de Cuba. Santo Domingo, 7-II-1855. AMAE, fondo Política, subfondo Política Exterior, serie R. Dominicana, Leg. H 2374 (Es copia).

${ }^{9}$ JIMENES, 1976, pp. 61 y 65.

${ }^{10}$ Welles, 1981, p. 140. 
Aunque el Congreso había enmendado de modo sustancial el proyecto de tratado que presentó el ejecutivo de Washington a la cámara, tras la reforma constitucional Santana había conseguido que la mayoría de los miembros del recién creado Senado Consultor fuesen adeptos suyos, por lo que podría volver a intentar la aprobación de un tratado que incluyese la cesión de la península y bahía de Samaná a los Estados Unidos.

Este temor hizo que los cónsules inglés y francés se lanzaran a una labor de zapa contra el gobierno, a fin de promover su substitución por Báez, quien, siendo mulato, no podía sentir simpatías - a juicio de estos funcionarios extranjeros- por una potencia esclavista, como lo era aún Estados Unidos ${ }^{11}$.

\section{LA SITUACIÓN POLÍTICA INTERNA DE LA REPÚBLICA DOMINICANA Y SUS IMPLICACIONES INTERNACIONALES}

Santana y su entorno más inmediato, dentro del cual había vuelto a ocupar un lugar muy relevante Tomás Bobadilla después de reconciliarse con el presidente, consideraron imprescindible reforzar aún más el poder ejecutivo. Ello se tradujo, sobre todo, en un drástico recorte de la capacidad de actuación del poder legislativo, y por ello plantearon una nueva reforma de la Constitución, la segunda en menos de un año. Se puede afirmar que el texto legal promulgado en diciembre de 1854 "fue hecho a imagen y semejanza del pensamiento santanista", de tal modo que "los derechos humanos y el ejercicio de las libertades fundamentales quedaron fuera del mismo" 12 .

Uno de los aspectos que más contribuyeron a la ausencia de una verdadera separación de poderes y a que el nuevo régimen se redujese a una mera farsa de la democracia representativa, fue la transformación del Congreso bicameral en una sola cámara legislativa, el denominado Senado Consultor, que integraban tan solo siete miembros. Resulta muy significativo que apenas hubiera oposición al proyecto autocrático de Santana por parte de los propios congresistas, ni siquiera propuestas alternativas en un sentido menos restrictivo. Algunos representantes del liberalismo, aun siendo conscientes de que "el nuevo estado necesitaba proveerse de un cuerpo político que creara un marco institucional y definiera el alcance del gobierno", pensaban que "esta meta no podía ser alcanzada mediante la simple promulgación de una constitución o adoptando, como lo hicieron, el modelo de organización política desarrollado en Europa y los Estados Unidos", sino que "más bien, se necesitaba una estructura legal en consonancia con la realidad nacional". Sin embargo, este punto de vista realista defendido por algunos intelectuales y políticos de signo liberal fue siempre muy minoritario, y la mayor parte de las veces "los dominicanos ignoraron la relación entre lo ideal y lo posible"13.

\footnotetext{
${ }^{11}$ JiMENES, 1976, p. 65.

12 CRuz, 1994, p. 56.

${ }^{13}$ Cross, 1984, p. 111.
} 
Cabe resaltar que hubo importantes figuras que criticaron "la adopción mecánica del modelo democrático republicano", como por ejemplo el diputado Benigno Filomeno Rojas, quien en 1854 dirigió a los demás legisladores estas palabras:

Tened presente, os ruego, y evitad con el mayor esmero, el legislar por imitación, porque un pueblo con una pequeña población esparcida por un vasto territorio, no puede gobernarse con las mismas leyes hechas para otros más adelantados en la escala del progreso ${ }^{14}$.

A pesar de todo, Rojas también se plegó a la voluntad de Santana y su camarilla, y en el debate del proyecto de reforma constitucional aquél se limitó a decir que "no haría ninguna objeción... porque supone en él un plan político y que, al alterarlo con cualquier modificación, se destruiría el objeto que se propone el Ejecutivo"15. Sin entrar a juzgar la posible valoración que le mereciera dicho objeto, el mismo Rojas se convirtió de este modo en coautor de una reforma restrictiva y que suponía un paso atrás en la construcción de un régimen político respetuoso de las libertades. Tras la aprobación de la nueva Constitución, y con una cámara legislativa reducida a la mínima expresión, Santana tuvo aún más fácil controlar todo el poder sin preocuparse de la opinión del Senado Consultor, que se veía obligado a actuar en plena armonía con el ejecutivo, quedando así convertido en un mero apéndice de éste.

En opinión de San Just, el gobierno dominicano estaba favoreciendo "el plan del enviado" norteamericano, consistente "en atacar la validez del Congreso que rechazó la ratificación de su tratado", para poder presentarlo de nuevo "y con la cláusula de la cesión de Samaná a los Estados Unidos haciéndole ratificar sigilosamente por el Senado Consultor". El agente comercial preveía que dicho plan podría llevarse a cabo con facilidad "a menos que antes de la reunión del Senado consultor se presentaran aquí algunas fuerzas navales inglesas, francesas y aún mucho mejor españolas". Otra opción que dejaba abierta también era la de promover el regreso inmediato de Báez a Santo Domingo, "pues no hay que dudar que su sola presencia bastaría a derrocar el actual gobierno vendido enteramente a Cazneau sin esceptuar [sic] al mismo presidente Santana"16. Sin embargo, no todos los españoles residentes en la República Dominicana eran partidarios de la vuelta de Báez al poder. El marqués de Olivares se contaba entre ellos, y en una interesante carta dirigida al capitán general de Cuba expresó sus opiniones acerca de la actuación de los franceses en la isla, así como sobre Báez y Santana:

Las cuestiones en este momento de la República Dominicana son mui [sic] arduas con el cónsul de Francia y parece que los franceses quieren buscar pretextos insignificantes para chocar con este gobierno que no está más que por el progreso de la Reppca. (sic) y se conoce que la Francia quiere proteger al Sor. Báez ex presidente, al enemigo mortal de todos los españoles, diré de todos aquellos que no son aduladores [...].

\footnotetext{
${ }^{14}$ Ibidem, p. 129.

${ }^{15}$ JiMENES, 1976, p. 64.

${ }^{16}$ Carta de Eduardo San Just al gobernador de Cuba. Santo Domingo, 13-II-1855. AMAE, fondo Política, subfondo Política Exterior, serie R. Dominicana, Leg. H 2374 (Es copia).
} 
A mi poco entender creo que los franceses bajo cuerda protegen a los haitianos y [tienen] la vista sobre el Pto. de Samaná [...].

[España] debe abrir los ojos sobre esta Reppca. y dar su protección a este país. Conviene a España no abandonar esto por ningún pretexto y mucho menos en el día con las miras particulares de los Estados Unidos. [...] El valiente Santana, el héroe de Las Carreras es digno [de] que la Madre Patria vele sobre él dándole su protecsión [sic], y mucho más cuando es un verdadero español ${ }^{17}$.

Desde Santo Domingo, Olivares veía la amenaza de Francia contra Santana como una forma de alcanzar sus propios objetivos, para lo cual necesitaba instalar de nuevo a Báez en la presidencia. En cuanto a la supuesta protección que los franceses brindaban a Haití, de la cual también se hacía partícipe a Gran Bretaña debido a la beligerancia de su gobierno a favor de la abolición de la trata de esclavos, y de la esclavitud misma, existen pruebas que hacen dudar de la sinceridad de los representantes de ambos países con respecto a la defensa de la soberanía e integridad territoriales de la República Dominicana frente a sus vecinos haitianos. De hecho, mientras el gobierno dominicano se mantuvo negociando con Cazneau, se buscaron todos los modos posibles de frustrar la firma de un tratado, sin reparar en sus posibles efectos negativos para la independencia dominicana. Los cónsules francés y británico alertaron al emperador Soulouque acerca de los peligros que entrañaba para Haití dicho tratado, y le infundieron así un temor que "estaba destinado a producir consecuencias más graves que las calculadas, probablemente, por los agentes europeos"18.

En estas circunstancias, el representante español en Puerto Príncipe, Dionisio Cruzat, expresó en una carta enviada al ministro de Estado su perplejidad ante la necesidad de encontrar el medio más apropiado "de evitar la consumación del proyecto norteamericano". Cruzat preguntó qué consejo debía dar a Soulouque "para impedir la catástrofe que le amenaza así como a nuestras Antillas", y se respondió a sí mismo que la guerra o invasión haitiana no convenía a España, ni entraba en su política "promoverla a pesar de que quizás fuese el mejor modo de frustrar los planes de Cazenau [sic]". Acto seguido reconoció no estar tan seguro de la eficacia de semejante medida de presión, puesto que el emperador haitiano, quien soñaba con la reunificación de la isla, aunque quisiera no podía emprender la reconquista de la otra parte, puesto que no era capaz de reunir suficientes fuerzas y material de guerra ${ }^{19}$.

Por último, el agente español indicó al ministro que de todo ello "están enterados y firmemente convencidos los dominicanos, por cuyo motivo sería fútil el amenazarlos con la invasión haitiana", y al final señaló, como única solución posible, que "no hay más que un hombre, el Gral. ex presidente Báez, si estuviese allí, que

\footnotetext{
${ }^{17}$ Carta del marqués de Olivares al gobernador de Cuba. Santo Domingo, fecha ilegible. AMAE, fondo Política, subfondo Política Exterior, serie R. Dominicana, Leg. H 2374.

${ }^{18}$ WeLles, 1981, p. 156.

${ }^{19}$ Carta de Dionisio Cruzat al ministro de Estado. Puerto Príncipe, 28-II-1855. AMAE, fondo Política, subfondo Política Exterior, serie R. Dominicana, Leg. H 2374.
} 
pudiese trastornar el proyecto Santana-Cazenau". Cruzat le informó también de que "el mismo Santana amenazado con una revolución ha tenido que retirarse en su quinta del Ceibo [sic], de donde hace algunos meses no sale" 20 .

Entre el 9 y el 10 de febrero dos barcos de guerra norteamericanos hicieron acto de presencia frente al puerto de Santo Domingo, y Cazneau intentó llevar a cabo una maniobra que no surtió el efecto por él deseado. El enviado estadounidense trató de aprovechar esta circunstancia, que quizás consideró como la última oportunidad que se le presentaba para salir con éxito de su misión ante el gobierno dominicano, al que planteó un ultimátum por el que lo conminaba a dar una respuesta a sus demandas en un plazo máximo de cuarenta y ocho horas. Todo ello, claro está, bajo la amenaza más o menos tácita que suponía la presencia de los buques de la armada norteamericana en las aguas de la propia capital dominicana. Sin embargo, la operación resultó un rotundo fracaso, puesto que el comandante del vapor San Jacinto, "a las tres horas de haber llegado y después de haber tenido una entrevista con Cazneau, dispuso su salida", sin esperar la respuesta del gobierno dominicano, que se sintió así algo aliviado de esa presión. No obstante, el agente español en Santo Domingo señaló en una comunicación dirigida al gobernador de Cuba el 13 de febrero que "las circunstancias actuales" eran extremadamente críticas. "Estos buques y otros que deben presentarse de un momento a otro, vienen a ofrecer con su presencia un apoyo a las pretensiones de Cazneau"21.

El día 15, el gobierno dominicano respondió a Cazneau que ya había enviado a Washington el conjunto de enmiendas propuesto por el Congreso al texto del tratado, de modo que el agente norteamericano quedó totalmente desautorizado, por lo que no tuvo más remedio que regresar a su país con las manos vacías. Las palabras de San Just en su carta del 21 de marzo de 1855 al gobernador de Puerto Rico transmitían "bastante tranquilidad" con relación a "nuestros asuntos", puesto que el agente de los Estados Unidos había sido

[...] desaprobado y destituido por su Gobierno, con sentimiento de los individuos que componen el Gavinete [sic] Dominicano, tanto más que por sus simpatías hacia dichos Estados se han enagenado [sic] las de las Potencias Occidentales de Europa y hoy no saben de dónde asirse ${ }^{22}$.

La complicada situación interna de la República Dominicana, no obstante, seguía agravándose y San Just comentaba al gobernador de Puerto Rico el extraño clima que se respiraba en Santo Domingo, ya que "durante los últimos quince días las cuestiones políticas de este país han quedado sumidas en el más profundo silencio". Esa aparente tranquilidad no podía ocultar a los ojos del representante español la existencia de "cierto malestar continuo en la población a causa de la miseria que de día en día

\footnotetext{
${ }^{20}$ Ibidem.

${ }^{21}$ Carta de Eduardo San Just al gobernador de Cuba. Santo Domingo, 13-II-1855. AMAE, fondo Política, subfondo Política Exterior, serie R. Dominicana, Leg. H 2374 (Es copia).

${ }^{22}$ Carta de Eduardo San Just al gobernador de Puerto Rico. Santo Domingo, 21-III-1855. AMAE, fondo Política, subfondo Política Exterior, serie R. Dominicana, Leg. H 2374 (Es copia).
} 
va haciendo progresos", por lo que también dio cuenta a ese alto funcionario de los rumores que circulaban, según los cuales el gobierno dominicano "está amenazado de un golpe de mano que tiende a derrocarlo, lo que no es de estrañar [sic] atendido [sic] a la manera en que administra el país" ${ }^{\prime 23}$. La sospecha se hizo realidad y el 25 de marzo, tan sólo cuatro días después de que San Just hubiese informado de esa posibilidad, estalló una insurrección a favor de Báez, encabezada por los generales Pelletier y Duvergé, y por otras relevantes figuras de la política dominicana tales como Pedro Ramón de Mena y Francisco del Rosario Sánchez. Este movimiento había logrado aglutinar no sólo a los baecistas, sino también a un numeroso grupo de descontentos, entre los cuales se encontraban tanto antiguos partidarios del presidente como otras personas que "sin ser militantes del baecismo, eran hostiles a Santana"24.

La actitud favorable a Báez que habían mostrado los representantes diplomáticos de las potencias europeas constituyó un factor coadyuvante para que los dirigentes de la oposición al régimen de Santana se decidieran a tomar las armas con el fin de provocar su caída. El general Antonio Duvergé, uno de los más importantes estrategas de las luchas libradas contra Haití durante los primeros años de la independencia, era "un hombre de posición política independiente que había sido perseguido por Santana y se encontraba confinado en la región oriental del país". Desde dicha región pretendía sumarse, junto a otros partidarios del levantamiento, a los insurrectos de la capital, dirigidos por Pelletier y Mena, pero la conspiración fue descubierta antes de materializarse, y el propio Santana, quien aún se encontraba en su hacienda de El Seibo, ordenó el arresto del general y el de los otros conjurados, así como la posterior ejecución de Duvergé, uno de sus hijos y un ciudadano español de origen catalán apellidado Dalmau ${ }^{25}$. Otro español que se vio envuelto en estos hechos fue José Braulio Camoin, que era cuñado de Báez y fue detenido como sospechoso de colaborar en el abortado movimiento revolucionario.

\section{LAS REPRESALIAS DEL RÉGIMEN DE SANTANA CONTRA SÚBDITOS ESPAÑOLES Y LA POLÉMICA EN TORNO A LA MATRÍCULA CONSULAR}

En tales circunstancias, y debido a la presunta implicación de dos súbditos españoles en las mismas, San Just se dirigió al ministro dominicano de Relaciones Exteriores, Juan Nepomuceno Tejera, en sucesivas comunicaciones de las que éste a su vez remitió copia a Madrid, acompañadas de una protesta por lo que consideraba injerencia del agente comercial español en los asuntos internos de la República Dominicana. En su carta del 2 de abril, San Just recriminó al ministro el "atropello cometido en la persona del súbdito español D. José Braulio Camoin”, y se quejó además de que aunque el gobierno dominicano le había asegurado que

\footnotetext{
${ }^{23}$ Ibídem.

${ }^{24}$ JiMENES, 1976, p. 66.

${ }^{25}$ Ibidem.
} 
[...] semejante medida había sido sin duda llevada a cabo por ignorar que el citado individuo fuese súbdito de S. M. [...] han transcurrido más de cuarenta y ocho horas después de su arresto, sin que se le haya aún notificado la causa que lo motivó ${ }^{26}$.

Finalmente, dada su condición de "protector de las personas e intereses de los súbditos de S. M. en este territorio", el agente español expresó su deber de apoyar la protesta que Camoin le había hecho llegar ${ }^{27}$. Dos semanas después, pese a no haber recibido contestación alguna a su anterior comunicación, San Just volvió a dirigirse a Tejera a fin de confirmar los rumores según los cuales el 11 de abril había sido ejecutado el ciudadano español Pedro Dalmau en la provincia de El Seibo, y solicitarle que, en caso de ser ciertos, le enviase "una copia de los trámites" que se habían seguido en el juicio contra él ${ }^{28}$. En su respuesta a San Just, el ministro Tejera le informó de que la causa que motivó el arresto de Camoin, "dominicano de origen, casado con dominicana", establecido desde hacía "largo tiempo en el país, aunque nacido y emigrado de la vecina Isla de Puerto Rico", no se había sustanciado aún. Por si todos estos datos biográficos de Camoin no resultasen suficientes, Tejera explicó también que dicho súbdito español se había presentado en Santo Domingo como descendiente de dominicanos, razón por la cual "obtuvo diferentes destinos públicos" y se lo consideraba dominicano a todos los efectos. A continuación, Tejera se refirió al caso de Dalmau y confirmó la noticia de su condena a muerte "en virtud de una sentencia legalmente dada, y por habérsele probado en juicio estraordinario [sic] o sumario criminal, su complicidad en el crimen de conspiración contra la seguridad del Estado". El ministro señaló además lo siguiente:

Que cual [sic] que fuese el origen de dicho señor Dalmau, él abrazó la causa dominicana, y por su espontánea voluntad tomó las armas y pidió incorporarse en el ejército, obteniendo después diferentes empleos consejiles [sic] y últimamente el de elector de provincia. Que el gobierno le consideró desde su voluntaria incorporación en las filas dominicanas como tal, sin que él alegase en ninguna circunstancia tener otra nacionalidad ${ }^{29}$.

Las explicaciones dadas por Tejera no satisficieron en absoluto a San Just, por lo que éste comunicó al ministro de Estado la difícil situación en que le habían colocado los acontecimientos que estaban teniendo lugar en la República Dominicana. En su

${ }^{26}$ Carta de Eduardo San Just al ministro de Relaciones Exteriores de la República Dominicana. Santo Domingo, 2-IV-1855. AMAE, fondo Política, subfondo Política Exterior, serie R. Dominicana, Leg. H 2374. El documento es una copia firmada por Tejera.

27 Ibídem.

${ }^{28}$ Carta de Eduardo San Just al ministro de Relaciones Exteriores de la República Dominicana. Santo Domingo, 16-IV-1855. AMAE, fondo Política, subfondo Política Exterior, serie R. Dominicana, Leg. H 2374. El documento es una copia firmada por Tejera.

${ }^{29}$ Carta de Juan Nepomuceno Tejera al agente comercial de España en Santo Domingo. Santo Domingo, 19-IV-1855. AMAE, fondo Política, subfondo Política Exterior, serie R. Dominicana, Leg. H 2374. El documento es una copia firmada por Tejera. 
despacho del 5 de mayo hizo un relato pormenorizado de los hechos que condujeron a la ejecución de Pedro Dalmau, quien

[...] fue preso en su casa vivienda, ranchería llamada Gato, Común de Higüey a la una de la noche del 26 al 27 de Marzo, cuando no podía saberse aún el complot que se dijo fraguado en ésta ${ }^{30}$.

Con respecto al último dato mencionado, el agente de España en Santo Domingo estaba en un error, puesto que Santana, "allá en su retiro, tuvo aviso de la conspiración antes que las autoridades de la Capital" 31 .

Sin embargo, la narración de San Just parece ajustarse a la realidad de los hechos en los demás aspectos relacionados con la detención de Dalmau, como por ejemplo la irregular circunstancia de que había permanecido en la cárcel "hasta que le sacaron para el patíbulo, sin que nadie le tomase ninguna declaración ni se le llamase para nada ante los jueces”. El agente señaló que, según la información de la que disponía, por fin el día 8 de abril se notificó al detenido "la acusación fiscal y ésta fue la primera noticia que él tuvo de los ridículos motivos" por los que se le había detenido. Desde ese momento, se aceleró el curso de los acontecimientos que desembocaron en su condena a muerte, cuya secuencia detalló San Just al ministro de un modo exhaustivo: el día 9 por la noche fue un soldado a la cárcel a decir a Dalmau "que le habían hecho levantar de la cama" para que fuese a defenderlo. Sin embargo, el soldado "no quería aceptar la defensa porque era completamente ignorante y no sabría hablar delante de los jueces". Dalmau respondió a su abogado forzoso que "era igual el que la aceptase o no, porque de nada había de servir la defensa". Durante el simulacro de juicio, que se celebró en ausencia del acusado, el improvisado defensor se limitó a "decir a la Comisión que el denunciador y los testigos eran deudores y enemigos personales de Dalmau", tras de lo cual "le hicieron callar y a las tres de la madrugada los jueces habían proferido la sentencia". El día 11 fue fusilado, y aunque el gobierno dominicano afirmaba en la Gaceta "que los condenados no apelaron al recurso en gracia que la ley les concedía", había "mentido descaradamente respecto a Dalmau", ya que éste "hizo su petición, desde la cárcel escrita de su puño y letra", pero Santana se negó a recibirla. San Just indicó también que otro español, natural de Barcelona, Manuel Paler, el cura párroco de El Seibo, tras oír la confesión de Dalmau y otros había intercedido en su favor ante Santana, aunque sin resultado alguno, y concluyó con las siguientes palabras el relato de cómo se había consumado ese "horrible asesinato":

El gobierno de S. M. sabrá apreciar lo abominable de este hecho, el cual reclama pronta vindicta, y no dejará de tender una mirada de justa protección a la viuda y a los hijos de un español tan inicuamente asesinado, en un país al cual todavía España no ha renunciado sus lejítimos [sic] derechos, dándose un ejem-

\footnotetext{
${ }^{30}$ Carta de Eduardo San Just al ministro de Estado. Santo Domingo, 5-V-1855. AMAE, fondo Política, subfondo Política Exterior, serie R. Dominicana, Leg. H 2374.

${ }^{31}$ Welles, 1981, p. 155.
} 
plo para que en lo sucesivo no se atropelle como hasta aquí de una manera tan indigna a los súbditos españoles ${ }^{32}$.

La disputa diplomática desatada entre el agente comercial de España en Santo Domingo y el gobierno dominicano como consecuencia de estos hechos hizo que el ministro de Relaciones Exteriores de la República viese la necesidad de comunicar directamente al ministro español de Estado su versión de los mismos, así como la opinión que le merecía la actuación de San Just en esta crisis. Según Tejera, el gobierno dominicano lamentaba "verlo seguir un sistema cuyos motivos no le es posible descubrir y del que infaliblemente resultaría [muy a pesar suyo] alterarse las buenas relaciones" existentes entre ambos países. El ministro señaló además que no había ninguna razón que permitiera a dicho agente "reclamar como súbditos de S. M. a los individuos mencionados en sus protestas", y apoyó esta aseveración en los mismos argumentos que ya había utilizado en ocasiones anteriores para rebatir a San Just, aunque sin aportar ninguna base sólida para justificar unas medidas del gobierno dominicano cuya legalidad era más que discutible. En este sentido, el propio Tejera reconoció que "Camoin fue preso como hermano político" de Báez, "en favor del cual se tramó la conjuración", y que Dalmau había sido "sentenciado y ejecutado en virtud de un juicio estraordinario [sic]", a lo que añadió que "en circunstancias críticas y apremiantes todo Gobierno procede sumariamente en la averiguación y castigo de semejantes hechos sin que se les califique de crueles". Al final de su despacho, el ministro llamó la atención de su homólogo español acerca del vacío legal en que se encontraban estos individuos, y le informó de que San Just no había participado ni directa ni indirectamente al ejecutivo de Santo Domingo

[...] la disposición que le comunicare el de Madrid para matricular como súbdito [sic] de S. M. a los peninsulares e insulares residentes largos años en ésta, y tenidos y habidos como dominicanos por adopción ${ }^{33}$.

Por último, Tejera expresó su esperanza de que "al imponerse de tan lamentables acontecimientos" el gobierno español sería "imparcial, y por consiguiente justo con el de la República", cuyo mayor deseo era "mantener las relaciones de amistad y buena inteligencia" entre los dos países ${ }^{34}$. No obstante, pese a la voluntad apaciguadora del gobierno dominicano, la situación empeoró más si cabe cuando el agente comercial español insistió de nuevo en sus protestas ante ese gobierno, al que hacía responsable "del ultraje hecho a la honra del súbdito español D. José Braulio Camoin, así como de todos los daños y perjuicios" que se le hubieran ocasionado "a consecuencia de su inmediato encarcelamiento y violenta espulsión [sic] del país". San Just protestaba sobre todo "contra el insulto inferido" a su per-

\footnotetext{
${ }^{32}$ Carta de Eduardo San Just al ministro de Estado. Santo Domingo, 5-V-1855. AMAE, fondo Política, subfondo Política Exterior, serie R. Dominicana, Leg. H 2374.

${ }^{33}$ Carta de Juan Nepomuceno Tejera al ministro de Estado. Santo Domingo, 7-V-1855. AMAE, fondo Política, subfondo Política Exterior, serie R. Dominicana, Leg. H 2374.

${ }^{34}$ Ibídem.
} 
sona, como representante de España, "al negarle la entrada en la prisión en donde se hallaba un súbdito de S. M. Católica"35.

A los pocos días se originó una nueva polémica, cuya causa era una vez más la supuesta violación de los derechos de otro ciudadano español, llamado Florentino Sardá, hijo de Francisco Sardá y Carbonell, quien también era oriundo de Cataluña y estaba, "como debe naturalmente suponerse, inscrito en la Matrícula" abierta en la agencia comercial. El representante de España señaló al ministro Tejera que el gobierno dominicano, a pesar de conocer la nacionalidad de dicho individuo, había obligado a algunos de sus hijos a cumplir el servicio militar, y a continuación le advirtió de que su presencia en la República Dominicana como agente reconocido del gobierno español sería "bastante para hacer cesar tamaños desafueros", y que reclamaría "a los súbditos de España si forzosamente" se les quería "obligar a servir" al gobierno dominicano ${ }^{36}$.

\section{LA NUEVA ACTITUD DE GRAN BRETAÑA Y FRANCIA FRENTE AL TRATADO DOMINICO-NORTEAMERICANO}

En medio de la agitación política reinante en el país, el general Santana expresó al agente comercial de los Estados Unidos en Santo Domingo, Jonathan Elliott, su "esperanza de que las negociaciones para un tratado" con ese país estuviesen todavía "pendientes de realización". El 5 de mayo de 1855 Elliott informó al secretario de Estado norteamericano acerca de esta disposición favorable de Santana, y le aseguró además que los Estados Unidos podían tener allí todo lo que desearan. Pese a ello, el agente comercial indicó a Marcy que el tratado dominico-español ya había sido concluido, y que su punto principal era que no se permitiría a "extranjeros poseer parte alguna" del territorio dominicano ${ }^{37}$. Por su parte, y ya desde Washington, Cazneau también facilitó al secretario Marcy la información de la que disponía, acerca de la inestable situación política dominicana, y señaló como causa de la rebelión contra Santana las intrigas de Gran Bretaña y Francia. Según aquél, ambas,

[...] indudablemente en cooperación con Haití, y el partido de los negros encabezado por Báez, trataban de extinguir la República Dominicana y de convertir a la isla entera en una dependencia africana [...]. Con este fin, los agentes en Santo Domingo dieron toda ayuda posible al partido de Báez y de los negros.

[...] Cuando por fin la revolución se intentó y fue suprimida, los líderes rebeldes fueron directamente a los consulados europeos a pedir protección y allí fueron recibidos y hospedados en desafío a los pedidos de las autoridades dominicanas de que debían

\footnotetext{
${ }^{35}$ Carta de Eduardo San Just al ministro de Relaciones Exteriores de la República Dominicana. Santo Domingo, 8-V-1855. AMAE, fondo Política, subfondo Política Exterior, serie R. Dominicana, Leg. H 2374. El documento es una copia firmada por Tejera.

${ }^{36}$ Carta de Eduardo San Just al ministro de Relaciones Exteriores de la República Dominicana Santo Domingo, 14-V-1855. AMAE, fondo Política, subfondo Política Exterior, serie R. Dominicana, Leg. H 2374. El documento es también una copia firmada por Tejera.

${ }^{37}$ LOCKWARD, 1987, pp. 277-278.
} 
rendirse para ser sometidos a juicio. Aun los que fueron apresados y condenados a muerte vieron que sus sentencias fueron perdonadas ante la demanda de los cónsules europeos, respaldados como de costumbre por una imponente fuerza naval ${ }^{38}$.

No sin razón, Cazneau afirmó también en su misiva, fechada el 9 de junio, que cualquiera que fuese "el ulterior destino de la República Dominicana", no se la podía "considerar competente para firmar tratados con otras naciones y cumplirlos", en tanto en cuanto los países europeos continuaran "gobernando" en sus asuntos internos y externos más importantes ${ }^{39}$. De hecho, la injerencia franco-británica aparecía como un importante factor que había dado impulso al levantamiento que pretendía derrocar a Santana, y el antiguo comisionado norteamericano lo relacionó directamente con la supuesta pretensión de los representantes de ambas potencias de unificar toda la isla bajo el dominio de Haití, un país de población negra y cuyo gobierno prefería el entendimiento con los europeos antes que con los Estados Unidos, en donde la esclavitud aún estaba vigente. La actuación del agente español en Santo Domingo a lo largo de esta crisis no fue tan decisiva como la de los cónsules de Gran Bretaña y Francia, a juzgar por la ausencia de referencias al mismo en el comentario que hizo Cazneau de estos hechos. Sin embargo, la situación había comenzado a cambiar, como se deduce de la enérgica protesta de San Just ante los atropellos cometidos por el régimen de Santana contra los súbditos españoles implicados en los sucesos revolucionarios, aunque se trataba todavía de una reacción meramente defensiva.

El temor de las autoridades españolas a la presencia norteamericana en la República Dominicana era equiparable a su interés por evitar todo enfrentamiento directo con los Estados Unidos. Las comunicaciones de los gobernadores de Cuba y Puerto Rico son una muestra evidente de esta actitud, la cual no impidió que en algunas ocasiones se hiciesen eco de las preocupantes informaciones que les transmitían quienes conocían la realidad dominicana con mayor profundidad. En tal sentido, algunos despachos oficiales dejan traslucir una gama más amplia de elementos que también deben tomarse en cuenta, ya que permiten analizar esta compleja situación desde diferentes ángulos, como por ejemplo los aspectos sociales y económicos.

En efecto, el escaso desarrollo económico experimentado por la República Dominicana desde su nacimiento en 1844 constituía el principal motivo de insatisfacción para la inmensa mayoría de la población. Así se lo hizo ver San Just al gobernador de Puerto Rico a principios de 1855, cuando le escribió acerca de la "inquietud" que se advertía en ese país "por la carencia absoluta en que se halla de administración, de comercio y de agricultura en donde sus naturales" pudieran "encontrar los recursos necesarios para su subsistencia", que era "bien precaria por cierto". Con gran lucidez, y dejando de lado el fácil recurso a las intrigas de unos y las traiciones de otros para explicar las causas del anexionismo, el agente aseguró que no era fácil juzgar si verdaderamente existía o no una mayoría que prefería "a

\footnotetext{
${ }^{38}$ Ibídem, pp. 279-280. Las cursivas son del autor.

${ }^{39}$ Ibidem, p. 280.
} 
este estado de cosas, entregarse en manos de los norte-americanos" que ofrecían "sacar al país de semejante abandono" 40.

El gobierno español conocía de sobra que importantes sectores de la sociedad cubana apostaban por la anexión de esa isla a los Estados Unidos, como salida a la situación de dependencia colonial en que se encontraban con respecto a una metrópoli que no satisfacía sus demandas de mayor libertad en el plano político ni en el económico. Del mismo modo, no ignoraba que algo semejante pudiese estar sucediendo en la República Dominicana, y por ello el primer objetivo de la política española en las Antillas debía ser la eliminación de esa tendencia favorable a la anexión a los Estados Unidos, que existía de una forma más o menos latente en ambos casos. En una comunicación dirigida a Luzuriaga el 12 de marzo, el gobernador de Cuba señaló con precisión, y con la vista puesta siempre en la seguridad de la isla que tenía bajo su mando, cuál debía ser en su opinión la conducta del agente español en Santo Domingo:

Obrar en completa combinación con los cónsules francés e inglés. Limitarse a favorecer sus intentos con su influencia y esfuerzos. Dejar a dichos funcionarios toda la iniciativa [...], y no aventurarse a dar por cuenta propia ningún paso. V. E. comprenderá que si éste era mi modo de pensar hace dos meses, con harta más razón lo será ahora, atendidas las circunstancias en que se halla esta Isla, cuya situación V. E. conoce hasta qué punto podrá afectar un acto que envolviese un choque ostensible a la política e intereses del gobierno de la Unión ${ }^{41}$.

Sin embargo, la coyuntura internacional había comenzado a cambiar, y ya no era posible confiar la defensa de Cuba y Puerto Rico tan sólo a la acción combinada de Gran Bretaña y Francia, como único medio de obstaculizar la agresiva política expansionista de los Estados Unidos en las Antillas. El primer paso había sido el envío de San Just y Cruzat, aunque con la intención de que ambos representantes se limitaran en todo momento a secundar la política diseñada por los ejecutivos de Londres y París, tal como pedía el general De la Concha. En la minuta de una comunicación dirigida por Luzuriaga al agente comercial de España en Puerto Príncipe, el ministro de Estado afirmó sin ambages que "uno de los principales objetos" que el gobierno español se había propuesto al establecer dos agentes, uno en Santo Domingo y otro en Haití, había sido "el prevenir los peligros" que pudiesen "amenazar a la isla de Cuba por el establecimiento de los anglo-americanos” en la República Dominicana. Luzuriaga le insistió en la necesidad de actuar en todo momento de acuerdo con las otras dos potencias europeas, a fin de "contener y alejar el peligro de una nueva guerra" entre haitianos y dominicanos. El ministro también dio instrucciones a Cruzat sobre la necesidad de impresionar al gobierno de Soulouque con la idea de que una vez establecidos los norteamericanos en Santo Domingo, "lo cual conseguirían fácil-

\footnotetext{
${ }^{40}$ Carta del gobernador de Puerto Rico al ministro de Estado. San Juan, 29-I-1855. AMAE, fondo Política, subfondo Política Exterior, serie R. Dominicana, Leg. H 2374 (Es copia).

${ }^{41}$ Carta de De la Concha al ministro de Estado. La Habana, 12-III-1855. AMAE, fondo Política, subfondo Política Exterior, serie R. Dominicana, Leg. H 2374 (Es copia).
} 
mente el día que de nuevo amenazaran las hostilidades" por parte de Haití, las razas que vivían en ambas partes de la isla serían "absorbidas por la invasora y fecunda nacionalidad anglo-americana"42.

El encargado de negocios de España en París fue el primero en dar la voz de alarma acerca del cambio de actitud del gobierno francés hacia el de los Estados Unidos, cuando el 14 de abril de 1855 informó al ministro de Estado de que por parte francesa ya no existía ningún temor a que un posible tratado entre la República Dominicana y los Estados Unidos fuese contrario a los intereses de Francia, España y Gran Bretaña. Dada la gravedad del asunto, se envió rápidamente copia de este despacho a San Just y a Cueto, agente plenipotenciario de España en Washington, quien a su vez indicó al ministro español de Estado que le parecía excesiva la confianza del gobierno de Napoleón III con respecto a las seguridades dadas por el secretario de Estado al conde de Sartiges, representante de Francia en la capital norteamericana. Cueto concluyó su comunicación con estas palabras:

Tengo motivo para creer que estas seguridades no han pasado de frases generales y vagas que a nada comprometen y que si Mr. Cazneau [...] no llegó a realizar sus miras de adquirir alguna parte del territorio Dominicano, fue por ineficacia de sus manejos y no por oposición del gabinete de Washington"43.

Por si la nueva posición de Francia no fuese suficiente motivo de preocupación para el gobierno español, pocos días más tarde fue el embajador en Londres quien advirtió de un giro similar por parte del gabinete británico, al informar de una entrevista que había mantenido con el subsecretario del Foreign Office, durante la cual dicho funcionario le dijo lo siguiente:

El gobierno inglés no se opondría, ni tenía para qué, a que los Estados Unidos celebrasen con Santo Domingo un tratado inofensivo de comercio - tal como era el proyectado- siempre que no envolviera la cesión ni ocupación de ningún punto del territorio dominicano; pero que aun esto le parecía difícil porque la legislación especial con respecto a los negros que rige en cada uno de los estados de la Unión imposibilitaba la celebración de un convenio bajo bases de reciprocidad ${ }^{44}$.

Estas últimas palabras encontraron su confirmación pocos meses más tarde en otras del secretario de Estado norteamericano, William L. Marcy, quien "debió comprender que el Senado, dominado completamente entonces por los estados esclavistas del sur, jamás aprobaría un tratado que contuviese las modificaciones insertadas en el proyecto de 1854 por el Congreso dominicano a petición del cónsul británico". En efecto, el artículo tercero del mencionado proyecto estipulaba que todos los ciudada-

\footnotetext{
${ }^{42}$ Carta de Luzuriaga al agente de España en Puerto Príncipe. Aranjuez, 12-IV-1855. AMAE, fondo Política, subfondo Política Exterior, serie R. Dominicana, Leg. H 2374 (Minuta).

${ }^{43}$ Carta de Cueto al ministro de Estado. Washington, 20-VI-1855. AMAE, fondo Política, subfondo Política Exterior, serie R. Dominicana, Leg. H 2374.

${ }^{44}$ Carta de Comyn al ministro de Estado. Londres, 24-IV-1855. AMAE, fondo Política, subfondo Política Exterior, serie R. Dominicana, Leg. H 2374.
} 
nos dominicanos, sin distinción de color, recibirían en los Estados Unidos el mismo tratamiento que los ciudadanos de ese país en la República Dominicana. Debido a la imposibilidad de que el Senado norteamericano aceptara semejante cláusula, el 9 de octubre de 1855 Marcy instruyó a su agente comercial en Santo Domingo para que insistiese ante el gobierno dominicano en la necesidad de omitirla, dado que "la paz y la seguridad de los estados del sur así lo exigían". El secretario de Estado aseguró al agente Elliott que en caso de que el gobierno dominicano aceptara eliminar esa condición, el ejecutivo de Washington "estaría dispuesto a concluir las negociaciones"45.

El gobierno español, al igual que los de Gran Bretaña y Francia, era consciente de que en cualquier momento podrían reanudarse las negociaciones para la firma de un tratado entre la República Dominicana y los Estados Unidos. Es más, ninguno de ellos tenía la menor duda de que Santana utilizaba esa amenaza como medida de presión cuando le convenía para defender sus propios intereses, aunque siempre lo hacía invocando la necesidad de obtener una protección eficaz frente a Haití. Así, poco tiempo después de que fracasara la intentona revolucionaria que había contado con el apoyo de los representantes diplomáticos de las tres potencias europeas, el agente español en Puerto Príncipe se hizo eco de los rumores más o menos interesados que circulaban por esa ciudad, según los cuales parecía que Santana había manifestado a los cónsules de Francia y Gran Bretaña que se echaría "voluntariamente en los brazos de los americanos" si no lo sacaban "mui [sic] pronto de la triste posición" en que se hallaba la República ${ }^{46}$.

\section{EL ESTABLECIMIENTO DE RELACIONES DIPLOMÁTICAS ENTRE ESPAÑA Y LA REPÚBLICA DOMINICANA}

En este contexto, no resulta extraño que el gobierno español continuase adelante con su plan de establecer relaciones diplomáticas plenas con la República Dominicana a pesar de las complicaciones que le transmitió San Just, ya que lo estimaba imprescindible para poder ejercer una influencia más directa sobre el gobierno dominicano, a fin de impedir un acercamiento entre éste y el de los Estados Unidos. También es fácilmente comprensible que el gobernador de Cuba manifestara una posición tan tajante frente al agente comercial de España en Santo Domingo, a quien censuraba con dureza porque, en su opinión, no tenía "las condiciones de reserva y circunspección" que requería el desempeño de la misión que se le había confiado. De la Concha expresó asimismo, en la comunicación que dirigió al ministro de Estado el 20 de junio, su temor a que la actuación de San Just no obtuviese "otro resultado que el de crear dificultades y complicaciones entre ambos gobiernos" ${ }^{\prime 47}$. Esto era algo que el gobernador no podía sino deplorar, puesto que los intereses de España en Cuba y

\footnotetext{
${ }^{45}$ Welles, 1981, p. 158.

${ }^{46}$ Carta de Dionisio Cruzat al ministro de Estado. Puerto Príncipe, 9-IV-1855. AMAE, fondo Política, subfondo Política Exterior, serie R. Dominicana, Leg. H 2374.

${ }^{47}$ Carta de De la Concha al ministro de Estado. La Habana, 20-VI-1855. AMAE, fondo Política, subfondo Política Exterior, serie R. Dominicana, Leg. H 2374 (Es copia).
} 
Puerto Rico habían conducido a que por fin el gobierno español tratase de estrechar sus relaciones con el dominicano lo máximo posible, y no era aceptable que el plan así trazado se viniera abajo justo en este momento por una serie de incidentes de importancia relativamente menor.

En junio de 1855 Luzuriaga fue sustituido al frente del Ministerio de Estado por Juan de Zabala, quien ocupó el cargo durante poco más de un año, hasta el final del llamado bienio progresista. La actitud del nuevo ministro ante las alarmantes noticias que le hizo llegar San Just, al poco tiempo de su toma de posesión, sobre el comportamiento del gobierno dominicano con respecto a los ciudadanos españoles residentes en ese país, puede calificarse como contemporizadora. Así, en la primera comunicación que dirigió al agente español en Santo Domingo con motivo de la prisión de Camoin, el 19 de junio Zabala indicó a aquél que procurase "adquirir noticias detalladas y fidedignas acerca del suceso" y que si sus averiguaciones probaran la información que ya tenía, y por consiguiente que Camoin resultase ser, como se presumía, inocente, debía apoyar "la protesta de éste con la energía propia del que tiene la razón y la justicia de su parte"48. Como es lógico, esta contestación al despacho de San Just fechado en Santo Domingo el 17 de abril llegó a su destino mucho tiempo después, concretamente el 22 de julio, por lo que durante los tres meses transcurridos entre una y otra fecha el agente comercial español tuvo que regirse en su modo de actuar por su propia intuición.

Mientras tanto, las negociaciones en torno al tratado de reconocimiento entre España y la República Dominicana continuaban su marcha sin apenas sobresaltos, como si ninguna perturbación que hallara en su camino pudiese obstaculizar la definitiva ratificación del mismo y el establecimiento de relaciones diplomáticas plenas entre los gobiernos de ambos países. El plenipotenciario de la República Dominicana Rafael María Baralt, natural de Venezuela y de madre dominicana. Tras fijar su residencia en Madrid años atrás, Baralt había obtenido la nacionalidad española, y la elección para dicho puesto de un súbdito español por parte del gobierno dominicano a juicio de Luzuriaga demostraba "bien a las claras que las relaciones" que se trataba de establecer debían tener "su más firme apoyo en la lealtad y buena fe" ${ }^{4}$. Pocos días después de la firma del tratado, que tuvo lugar el 18 de febrero de 1855, Baralt comunicó a Luzuriaga que al objeto de "acelerar el término de su ratificación" había decidido hacerlo llegar a Santo Domingo por medio de un comisionado especial que abreviara tiempo y ahorrase "discusiones enojosas" ${ }^{50}$. Este encargo recayó en la persona de José Antonio Álvarez-Peralta, cuyas gestiones dieron fruto con bastante rapidez, de modo que el 2 de mayo el Senado de la República aprobó en todas sus partes el tratado hispano-dominicano, según el despacho que el día 7 de dicho mes

${ }^{48}$ Carta de Zabala al agente comercial de España en Santo Domingo. Madrid, 19-VI-1855. Archivo General de la Administración, Alcalá de Henares (en adelante: AGA), fondo Asuntos Exteriores, caja 54/5224, Núm. 5.

${ }^{49}$ Carta de Luzuriaga a Baralt. Madrid, 18-I-1855. AMAE, fondo Política, subfondo Política Exterior, serie R. Dominicana, Leg. H 2374 (Minuta).

${ }^{50}$ Carta de Baralt al ministro de Estado. Madrid, 21-II-1855. AMAE, fondo Política, subfondo Política Exterior, serie R. Dominicana, Leg. H 2374. 
envió a Baralt el ministro dominicano de Relaciones Exteriores, quien resaltaba con acierto la principal ventaja que debía reportar a España esta nueva situación:

El gobierno español, al legalizar generosamente la existencia política de la República, ha estrechado los vínculos que la unen a España, y adquirido al mismo tiempo el más fiel amigo que puede tener en la vecindad de sus colonias ${ }^{51}$.

La respuesta por parte española no se hizo esperar. El ministro de Estado felicitó a Baralt el 26 de junio por la aprobación del tratado, al tiempo que le informó de que era intención del gobierno pedir en breve a las Cortes la autorización necesaria para su ratificación ${ }^{52}$.

Ese mismo día, cuando todo eran parabienes en las instancias oficiales, apareció un artículo editorial en el diario La España, en el que se expresaban las numerosas interrogantes que planteaba una situación política tan agitada como la dominicana. El editorialista indicó en primer lugar la necesidad de "regularizar cuanto antes" las relaciones diplomáticas hispano-dominicanas, "a fin de evitar en lo sucesivo las reyertas y disputas desagradables" a las que ya estaban dando lugar "la confusión y complicaciones en todo lo relativo a la nacionalidad". A continuación, aquél resumió los últimos sucesos ocurridos en la República Dominicana en los que habían estado presuntamente implicados los españoles Dalmau y Camoin, y comentó la difícil posición de San Just en todo este asunto:

Partiendo del supuesto de que Dalmau era español, y de que también lo es Camoin, el agente comercial de España en Santo Domingo ha dirigido al ministro de relaciones esteriores [sic] dominicano una nota, $[\ldots]$ en la cual $[\ldots]$ se reclama contra el fusilamiento del uno y el encarcelamiento del otro.

[...] El señor Tejera, ministro de relaciones esteriores, ha contestado sosteniendo que las dos personas en cuyo favor reclamaba el agente comercial eran dominicanos [...]. No considerando el agente comercial español satisfactorias estas aclaraciones ha vuelto a la carga con mayor energía si cabe que al principio ${ }^{53}$.

El periódico también señaló la urgencia con que debía abordarse un conflicto, el de la nacionalidad, que de no resolverse adecuadamente amenazaba con una serie de consecuencias muy graves para las Antillas españolas, cuya seguridad y protección eran el principal objetivo que se perseguía por medio del tratado recién firmado, y concluyó del siguiente modo:

Estamos muy lejos de reprobar [...] el celo de nuestros agentes en defensa de los súbditos españoles que se vean vejados o atropellados en país estranjero [sic]; pero ante

\footnotetext{
${ }^{51}$ Carta de Baralt al ministro de Estado. Madrid, s. f. AMAE, fondo Política, subfondo Política Exterior, serie R. Dominicana, Leg. H 2374.

${ }^{52}$ Carta de Zabala al plenipotenciario de la República Dominicana en Madrid. Madrid, 26-VI1855. AMAE, fondo Política, subfondo Política Exterior, serie R. Dominicana, Leg. H 2374 (Minuta).

${ }^{53}$ Editorial de La España, Madrid, 26-VI-1855, año VIII, Núm. 2.218 (edición de la mañana). AMAE, fondo Política, subfondo Política Exterior, serie R. Dominicana, Leg. H 2374.
} 
todo es indispensable que la cualidad de españoles esté suficientemente acreditada, a fin de que la bandera nacional no sirva para cobijar desmanes de aventureros que buscan su medro en discusiones civiles a que deberían ser completamente estraños [sic] [...]. Sería por lo tanto muy sensible que un agente comercial, probablemente sin instrucciones precisas para tratar asuntos de tan delicada especie, sentase doctrinas y precedentes que los estranjeros pudiesen invocar en contra nuestra. Por eso insistimos de nuevo en la necesidad de arreglar pronto estas cuestiones, estableciendo claramente y sin que haya lugar a interpretación, la nacionalidad de la conveniente matrícula que se abra al efecto ${ }^{54}$.

En la República Dominicana, lejos de calmarse los ánimos, la cuestión de la matrícula de los súbditos españoles seguía agriando cada vez más las relaciones entre San Just y el gobierno de ese país, hasta tal punto que el agente comercial dio rienda suelta a su indignación en las comunicaciones que mantenía con sus superiores inmediatos. En una de ellas, enviada al gobernador de Puerto Rico a finales de mayo, San Just denunció "el sistema de persecución contra todo lo que es español" ejercido por el régimen de Santana, del que afirmó que "arrojada ya la máscara" no se detenía, y todos los días un nuevo conflicto venía "a aumentar el protocolo de los ya consumados vejámenes". El agente justificaba este lenguaje tan duro debido a la gravedad de los hechos, y centró sus críticas en la situación de muchos españoles, quienes al llegar a la República Dominicana fueron obligados "a servir como soldados", razón por la cual habían reclamado la protección de la agencia comercial de España en Santo Domingo. San Just acusó al gobierno dominicano de negarse a entregarles sus pasaportes e incluso de arrestarlos en el cuartel a fin de que no pudieran informarle de ello, pero eso no era todo, sino que además el gobierno había amenazado a varias familias españolas que habían ido a la agencia para matricularse, haciéndoles saber que si se matriculaban las expulsaría del país. Al término de esta retahíla de agravios inferidos por el santanismo a los españoles residentes en la República Dominicana, el agente se despachó con las siguientes opiniones respecto a sus dirigentes políticos y a la potencia que, según él, los defendía y sostenía, que no era otra que los Estados Unidos:

Es inaudito [...] lo que pasa en este país, gobernado por una reunión de hombres sin fe ni pundonor, y si la nación española no se dispone a dar un ejemplo, no concibo qué ocasión más propicia pueda ofrecerse [...]. Santana sin embargo sigue impávido porque cuenta con la fuerza de los negreros armados ${ }^{55}$.

Estas noticias fueron remitidas por el gobernador de Puerto Rico a Madrid, adonde llegaron a mediados del mes de julio, con el tiempo justo para posponer la aprobación del tratado por las Cortes, en espera de una aclaración satisfactoria de los hechos que San Just había expuesto en su despacho. Sin embargo, no hubo tal aplazamiento y los trámites siguieron su curso sin la menor alteración sobre el calendario previsto. Así,

\footnotetext{
${ }^{54}$ Ibídem.

${ }^{55}$ Carta de Eduardo San Just al gobernador de Puerto Rico. Santo Domingo, 23-V-1855. AMAE, fondo Política, subfondo Política Exterior, serie R. Dominicana, Leg. H 2374 (Es copia).
} 
el 2 de julio el gobierno presentó en las Cortes el proyecto de ley por el cual solicitaba la autorización para ratificar el tratado de reconocimiento celebrado con la República Dominicana. El último requisito a fin de convertirlo en ley era su promulgación oficial, que tuvo lugar en El Escorial el 26 de julio ${ }^{56}$. Ese mismo mes el ministro de Estado comunicó a San Just el nombramiento de Antonio María Segovia como cónsul general y encargado de negocios de España en la República Dominicana ${ }^{57}$.

A mediados de agosto el jefe de la dirección política del Ministerio de Estado, Miguel de los Santos, respondió diversos despachos enviados por San Just. En ellos, éste había dado cuenta de la conducta del gobierno dominicano respecto a los ciudadanos españoles, a cuyos hijos se obligaba "a tomar las armas desde la edad de catorce años". De los Santos le transmitió instrucciones para que reclamase "de la manera más enérgica" contra tal abuso, y en respuesta a otro despacho del agente en Santo Domingo, le especificó que dichas reclamaciones se formularan "para proteger a todos los que verdaderamente" fuesen súbditos españoles. Aquél subrayó a San Just la necesidad de mantener una actitud firme frente a "la persecución" que el gobierno dominicano ejercía contra los ciudadanos españoles ${ }^{58}$.

\section{CONCLUSIONES}

Dentro de esta línea de firmeza en la defensa de los intereses españoles, resulta sin duda muy reveladora la activa política, no exenta de cierta agresividad, desplegada por el primer cónsul de España en Santo Domingo. En efecto, Segovia puso en marcha enseguida una intensa actividad contra el tratado dominico-norteamericano, cuya ratificación quedó en suspenso debido a las presiones que ejerció sobre el gobierno dominicano. La política intervencionista del diplomático español llegó incluso a provocar la caída de Santana y su sustitución por Báez, en octubre de 1856, al considerar que este era más favorable a los intereses de España, por su oposición a un acercamiento entre la República Dominicana y los Estados Unidos.

Esta tendencia de claro intervencionismo en los asuntos dominicanos constituye sin duda el principal y más inmediato precedente de la actuación diplomática española a comienzos de la década siguiente, que tuvo como consecuencia directa la anexión de Santo Domingo a España entre 1861 y 1865. Por último, puede afirmarse que tal actuación no se encuentra desvinculada en modo alguno del resto de la política internacional y colonial española, sino que es un reflejo de la permanente preocupación de la misma por preservar el dominio de España sobre Cuba y Puerto Rico, para lo cual era de vital importancia controlar, directa o indirectamente, el territorio dominicano.

${ }^{56}$ Los documentos son los siguientes: una minuta del 2-VII-1855 y la promulgación de la ley, dada en El Escorial con fecha 26-VII-1855. AMAE, fondo Política, subfondo Política Exterior, serie R. Dominicana, Leg. H 2374.

${ }^{57}$ Carta de Zabala al agente comercial de España en Santo Domingo. San Lorenzo, 16-VII-1855. AGA, fondo Asuntos Exteriores, caja 54/5224, Núm. 5.

${ }^{58}$ Cartas de De los Santos al agente comercial de España en Santo Domingo. Madrid, 14 y 16-VIII1855. AGA, fondo Asuntos Exteriores, caja 54/5224, Núm. 5. 


\section{REFERENCIAS BIBLIOGRÁFICAS}

CORTADA, James W.

1978 Two nations over time. Spain and the United States, 1776-1977. "Contributions in American History" Collection, n'. 74. Westport, London. Greenwood Press.

Cross Beras, Julio A.

1984 Sociedad y desarrollo en República Dominicana 1844-1899. Santo Domingo. Instituto Tecnológico de Santo Domingo.

Cruz SÁNCHEZ, Filiberto

1994 Historia de los medios de comunicación en República Dominicana. Santo Domingo. Editora El Nuevo Diario.

Hauch, Charles Christian

1996 La República Dominicana y sus relaciones exteriores 1844-1882. Santo Domingo. Sociedad Dominicana de Bibliófilos.

JiMENES GRULLón, Juan Isidro

1976 Sociología política dominicana 1844-1966. Vol. I (1844-1898). Santo Domingo. Taller.

LOCKWARD, Alfonso

1987 Documentos para la historia de las relaciones dominico-americanas. Vol. I (1837-1860). Santo Domingo. Editora Corripio.

MARTÍNEZ-FERnÁndeZ, Luis

1992 The Hispanic Caribbean between empires: 1840-1868. Ann Arbor (Michigan). University Microfilms International.

SÁNCHEZ ANDRÉs, Agustín

2007 "Una diplomacia defensiva: la política exterior española en el Caribe y el golfo de México entre 1865 y 1878". Hispania. Revista Española de Historia. vol. LXVII. n ${ }^{\circ}$. 226, pp. 487-516.

WelLes, Sumner

1981 La viña de Naboth. La República Dominicana 1844-1924. Vol. I. Santo Domingo. Taller. 